\title{
LA OBRA DE MARÍA ISABEL PÉREZ DE COLOSÍA
}

Un análisis, siquiera somero, de la obra historiográfica de la Dra. María Isabel Pérez de Colosía Rodríguez produce en quien la contempla una gran satisfacción, porque pone de relieve, más allá de una continua dedicación a la tarea investigadora, una capacidad de dar respuesta a diferentes entornos y ámbitos diversos del estudio del pasado y de aprovechar las distintas potencialidades que abren fuentes históricas generadas con una finalidad muy determinada.

La formación inicial de la Dra. Pérez de Colosía fue la propia de la Historia de América, y nunca ha abandonado su interés por el estudio de la América española y de sus relaciones con la parte europea de la Monarquía. A lo largo de su abundante bibliografía encontramos artículos sobre el indigenismo, sobre relaciones comerciales de los puertos andaluces, y en concreto del de Málaga con Hispanoamérica o el estudio de personajes de gran significación en el gobierno de los reinos de Indias.

Sin embargo buena parte de la investigación que ha llevado a cabo desde la universidad de Málaga se ha orientado en torno al eje de la Inquisición. En este ámbito, la obra de la profesora Colosía refleja los cambios acontencidos entre los historiadores que trabajan sobre los fondos documentales del tribunal del San Oficio en los últimos treinta años; estos cambios abarcan desde la ampliación de las perspectivas de análisis hasta la utilización de los fondos inquisitoriales para el estudio de cuestiones en principio alejadas de la persecución de la heterodoxia religiosa. Por supuesto que los trabajos de temática inquisitorial acometidos por Pérez de Colosía se refieren al territorio del tribunal residente en la ciudad de Granada y en ellos ha utilizado también documentación municipal para enriquecer la información proporcionada por los archivos propios del tribunal.

Entre los estudios centrados en el análisis de la propia Inquisición, Maribel Colosía se ha ocupado de distintos aspectos del tribunal del Santo Oficio, entre ellos su personal y de manera específica de los familiares, un grupo que ilumina la conexión de la jerarquía inquisitorial con los distintos grupos sociales, como muestra el caso del escultor Pedro de Mena. Como es lógico, nuestra autora se ha interesado por el momento culminante de la acción inquisitorial que era la celebración del auto de fe - al que uno de sus trabajos califica de celebración punitiva - y por las víctimas del mismo que eran los penitenciados. Siguiendo la metodología de los historiadores, ha identificado los distintos colectivos perseguidos y castigados por el tribunal. En la época en que se han centrado sus investigaciones, uno de los colectivos más caracterizados 
eran los criptojudíos o judaizantes. Pero en el ámbito territorial del reino de Granada los moriscos eran también objeto de la persecución del tribunal y figuran entre los sentenciados en los autos de fe, cuando no conseguían emigrar al Norte de África (otro aspecto que Colosía ha estudiado). En relación al grupo de los conversos de origen musulmán, Isabel Colosía ha podido ofrecer un balance de "moriscología" a partir de los estudios llevados a cabo desde la universidad de Málaga.

Las fuentes inquisitoriales no únicamente nos informan de cuestiones relativas a creencias o prácticas heterodoxas. Hace ya tiempo que se ha puesto de relieve su interés como fuente para el estudio de la sociedad, de los grupo sociales y de las mentalidades. Algunos grupos sociales eran susceptibles de atención especial por parte del Santo Oficio porque su procedencia geográfica les hacía posibles portadores de creencias o actitudes no permitidas: este era el caso de los esclavos y de los extranjeros. En el ámbito de la difusión de las ideas el deseo de los inquisidores por evitar la entrada de libros prohibidos exigía a menudo la inspección de navíos procedentes de puertos extranjeros, como eran los holandeses.

Por otra parte, la información recogida por la Inquisición con fines persecutorios puede constituir una fuente documental muy importante para el estudio de la Historia de las mentalidades, de la religiosidad popular, de relaciones de vecindad y de parentesco, o de la realidad social de la mujer, por ejemplo de sus condiciones laborales. Además de los diversos artículos que la autora ha dedicado a profundizar en las distintas líneas concretas que hemos indicado, escribió junto con Joaquín Gil Sanjuán un extenso artículo de 100 páginas sobre Málaga y la Inquisición durante la segunda mitad del siglo XVI, publicado en 1982 en un número monográfico de la revista Jábega. Posteriormente nos ha ofrecido una síntesis sobre la estructura y actuación de la Inquisición en el reino de Granada (2000).

En efecto, el espacio geográfico primordial sobre el que se ha aplicado la labor investigadora de Isabel Pérez Colosía está constituido por la ciudad de Málaga y el reino de Granada. Ha dedicado algún trabajo al estudio de la representación cartográfica del territorio, a la importancia del río Guadalmedina en el siglo XVIII, a la construcción y organización del puerto, a las fortificaciones y la arquitectura militar. De aquí ha derivado el interés por la Historia militar en sus diversas vertientes, como la topográfica y la labor de los ingenieros militares. De la realidad material del sistema defensivo propio de la ciudad de Málaga (perímetro amurallado, castillo de Gibralfaro) pasó a tratar de la importancia estratégica de Málaga en el Mediterráneo occidental durante el siglo XVI, en relación con la defensa del Estrecho y la presencia española en el Norte de África.

Pero el eje de las investigaciones de la Dra. Colosía con relación a Málaga se encuentra en el estudio de la estructura social de la ciudad en el siglo del Barroco. También ha realizado aportaciones puntuales sobre factores demográficos, sobre determinadas coyunturas económicas de crisis, sobre la actividad comercial del puerto, en relación con el tráfico de Indias en el reinado de Carlos I, o sobre la importancia 
del consumo de nieve, bien considerado en sí mismo o como generador de impuestos municipales. La historia del puerto de Málaga ha tenido para nuestra autora un interés particular, puesto de relieve tanto a través de sus propios trabajos como de las tesis doctorales dirigidas por ella. Además de los numerosos artículos de investigación sobre los aspectos indicados, ha colaborado con capítulos de síntesis en obras colectivas sobre la Historia de la ciudad.

Su interés por la Historia social no se ha limitado a la ciudad de Málaga sino que se extiende por el reino de Granada, y en ocasiones ha llegado hasta las famosas almadrabas del duque de Medinasidonia en Tarifa. O hasta La Carolina para presentarnos la visión que nos han dejado los viajeros extranjeros de la más emblemática de las Nuevas Poblaciones del reinado de Carlos III. En el propio reino de Granada ha investigado sobre aquella coyuntura decisiva que fue la rebelión de los moriscos de las Alpujarras de 1568, con el esfuerzo militar realizado por las ciudades primero y luego con el importante proceso de repoblación que siguió al conflicto y sus repercusiones sociales, incluido un recrudecimiento de la presión inquisitorial.

Aunque buena parte de la labor investigadora de María Isabel Pérez de Colosía se ha dedicado a grupos sociales desfavorecidos o perseguidos (y por ello más difíciles de conocer con precisión) también ha dejado su impronta en el estudio de los grupos privilegiados. Se ha ocupado de algunas élites de poder en Indias y en España. En este caso el principal objeto de estudio ha sido la propia ciudad de Málaga, sus regidores capitulares y sus corregidores. También algunos de sus obispos. Tanto ella como Joaquín Gil han dedicado sus esfuerzos al mejor conocimiento de aquel prelado singular de la segunda mitad del siglo XVII que fue el famoso Fray Alonso de Santo Tomás, sin olvidar a don Enrique de Guzmán.

Y todo ello sin olvidar su inicial formación americanista. América y Málaga se dieron cita en la personalidad de José de Gálvez y su grupo familiar de Macharaviaya. Isabel Pérez de Colosía junto con otros compañeros de la universidad de Málaga hizo una colaboración importante en la obra colectiva que se publicó en 1991 sobre aquel importante grupo de gobernantes de Indias.

La obra de María Isabel Pérez Colosía no se encuentra solamente en publicaciones situadas en Málaga y su entorno. Ni siquiera en Andalucía. Ha publicado en la Revista de Indias y en Hispania, ambas del Consejo Superior de Investigaciones Científicas, ha participado de manera asidua y activa en las reuniones científicas bianuales que celebra la Asociación (hoy Fundación) Española de Historia Moderna, ha publicado en revistas y actas de congresos organizados por la Universidad Nacional de Educación a Distancia y sus trabajos sobre los moriscos han visto la luz en Túnez.

Al realizar este rápido balance de la obra historiográfica de la profesora María Isabel Pérez de Colosía he pensado en el magisterio del gran historiador andaluz que fue don Antonio Domínguez Ortiz. Nuestra autora se ha ocupado también de minorías perseguidas de carácter socio-religioso (conversos y moriscos), se ha interesado por el comercio con América, ha contribuido al mejor conocimiento de la estructura social de 
las ciudades andaluzas en la época del Barroco, ha avanzado por los nuevos caminos que representa la Historia de las mentalidades, ha conjugado las aportaciones biográficas con las síntesis sociales. En suma en su obra se reflejan las tendencias y las influencias de toda una generación y todos nos felicitamos y la felicitamos por los resultados que ha conseguido y que nos ofrece como fruto de toda una vida de investigación.

Pere Molas Ribalta

Catedrático de Historia Moderna

Universidad de Barcelona 


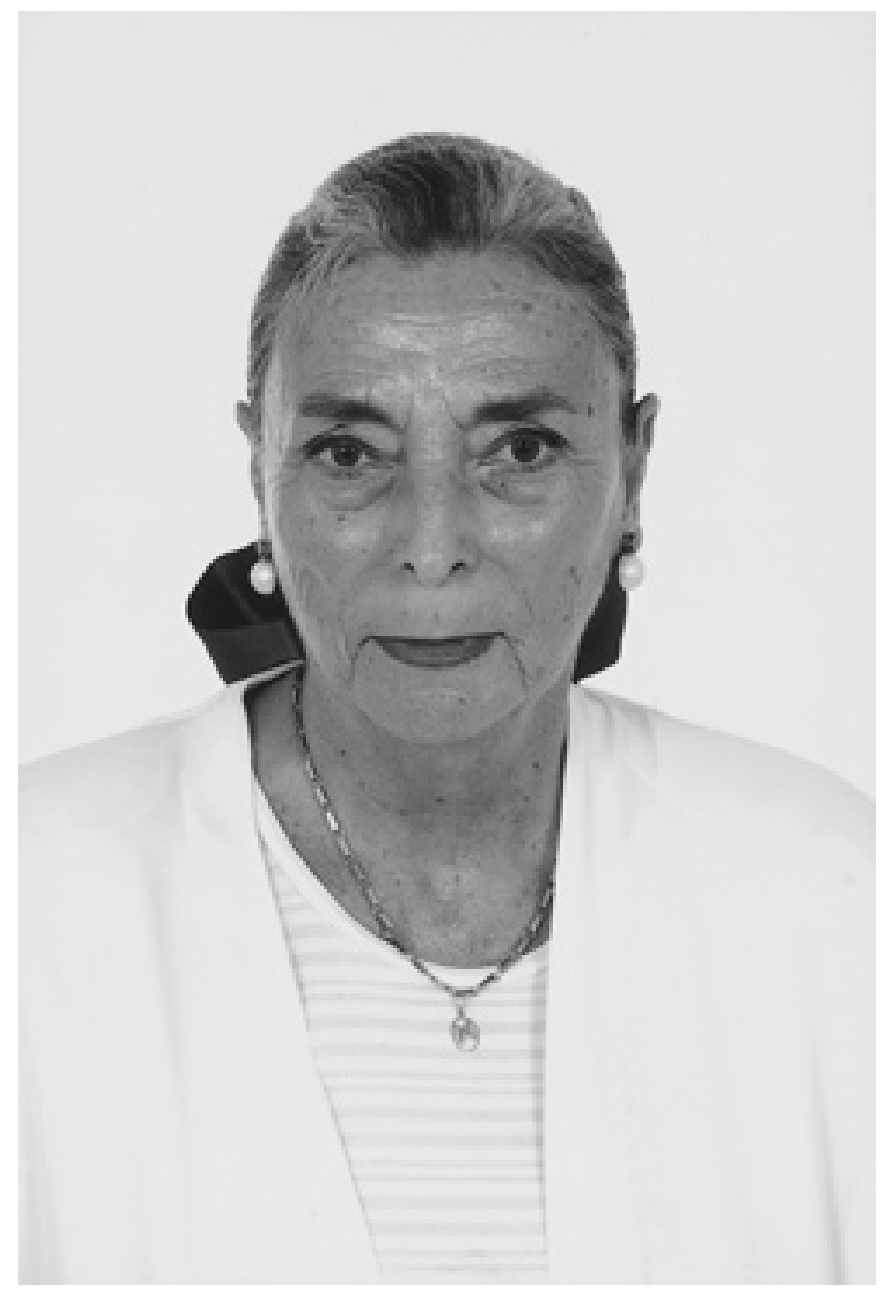


